\title{
Tubercle of Zuckerkandl
}

${ }^{1}$ Sabaretnam Mayilvaganan, ${ }^{2}$ Naval Bansal, ${ }^{3}$ Navneet Tripathi, ${ }^{4}$ Ashwini Reddy, ${ }^{5}$ Amit Agarwal

\section{ABSTRACT}

Endocrine Surgeon must have intimate knowledge about all anatomic variations of thyroid gland for performing safe thyroid surgery. Tubercle of Zuckerkandl is a posterior extrusion of the lateral thyroid lobes and it is a pointer to the recurrent laryngeal nerve and inferior parathyroid glands. We have discussed pertinent issues regarding tubercle of Zuckerkandl in this mini review.

Keywords: Pointer, Recurrent laryngeal nerve, Tubercle of Zuckerkandl.

How to cite this article: Mayilvaganan S, Bansal N, Tripathi N, Reddy A, Agarwal A. Tubercle of Zuckerkandl. World J Endoc Surg 2015;7(2):33-35.

\section{Source of support: Nil}

Conflict of interest: None

\section{INTRODUCTION}

Identification and preservation of recurrent laryngeal nerve (RLN) is a major concern for thyroid surgeons from the time of inception of thyroidectomy and even in this modern era of sophisticated technology still remains a myth at certain times even for the most experienced endocrine surgeon. Tubercle of Zuckerkandl (TZ) is considered a landmark which can help the surgeon in this regard. In recent times, there has been a surge of publications on TZ. We propose to address some issues in this mini review. ${ }^{1,2}$

\section{HISTORY}

Emil Zuckerkandl an anatomist in 1902, referred to this tubercle as 'Processus posterior glandulae thyroideae'. In 1867, German surgeon Otto Wilhelm Madelung described this as the posterior horn of thyroid. Till mid 1980s, the significant of this tubercle was not known. Now with refinement of thyroid surgery and with various new technologies, there is a rekindled interest in TZ. Pelizzo

\footnotetext{
${ }^{1}$ Assistant Professor, ${ }^{2-4}$ Senior Resident, ${ }^{5}$ Professor

${ }^{1-5}$ Department of Endocrine Surgery, Sanjay Gandhi Post Graduate Institute of Medical Sciences, Lucknow, Uttar Pradesh, India

Corresponding Author: Sabaretnam Mayilvaganan Assistant Professor, Department of Endocrine Surgery, Sanjay Gandhi Post Graduate Institute of Medical Sciences, Raebareli Road, Lucknow, 226014, Uttar Pradesh, India, Phone: +91 (0522) 2668004-8, Ext: 4409, e-mail:drretnam@gmail.com
}

in 1998 was the first to show the importance of $\mathrm{TZ}$ as landmark for RLN dissection. ${ }^{1}$

\section{DEVELOPMENT}

It indicates the point of embryologic fusion of the ultimo branchial body (lateral process) of the fourth pharyngeal pouch and the principal median thyroid process at the level of the second branchial arch. It is present in 60 to $90 \%$ of adult glands and subject to anatomical and radiologic variations. The reason of fusion of both the process is not known (Fig. 1). ${ }^{2-4}$

\section{INCIDENCE AND MORPHOLOGY}

Tubercle is present in 63 to $80 \%$ of patients undergoing thyroidectomy. It is mostly circular or triangular in shape. Pelizzo graded the tubercle as grade 0 — unrecognizable, grade I-only a thickening of the lateral edge, grade II$<1 \mathrm{~cm}$ and grade $\mathrm{III} \longrightarrow>1 \mathrm{~cm}$. Grade 0 is presentin 0 to $11.25 \%$, grade $\mathrm{I}-20 \%$, grade II $-56.25 \%$ and grade III $-12.5 \%$. Tubercle of Zuckerkandl is mostly located in the mid third of the thyroid lobe (88\%), however, it can be found in the lower part or on the upper third ${ }^{3-5}$ (Fig. 2).

\section{TUBERCLE OF ZUCKERKANDL AND ENTRANCE OF RECURRENT LARYNGEAL NERVE}

Tubercle of Zuckerkandl is usually situated at the middle third of lateral lobe in around 80 to $85 \%$ of the cases.

This has three types of relation with the entry of the recurrent nerve:

1. Tubercle of Zuckerkandl indicated the entry point of RLN or anterior branch.

2. They covered the entry point of RLN.

3. They can be above or below the entry point.

This is the reason, why surgeons can use this as an effective landmark. Most RLN injuries occurred just below the point where the RLN passed under the lower fibers of the Inferior constrictor muscle. In $91.9 \%$, nerve passes beneath the TZ. In 7.7\%, the nerve is found lateral. ${ }^{5}$ Such a situation is dangerous and if one does not recognize this situation on table, damage to RLN may result.

\section{PRESSURE SYMPTOMS}

The pressure symptom does not always appear due to the large size of the goiter, but small goiter with a higher 


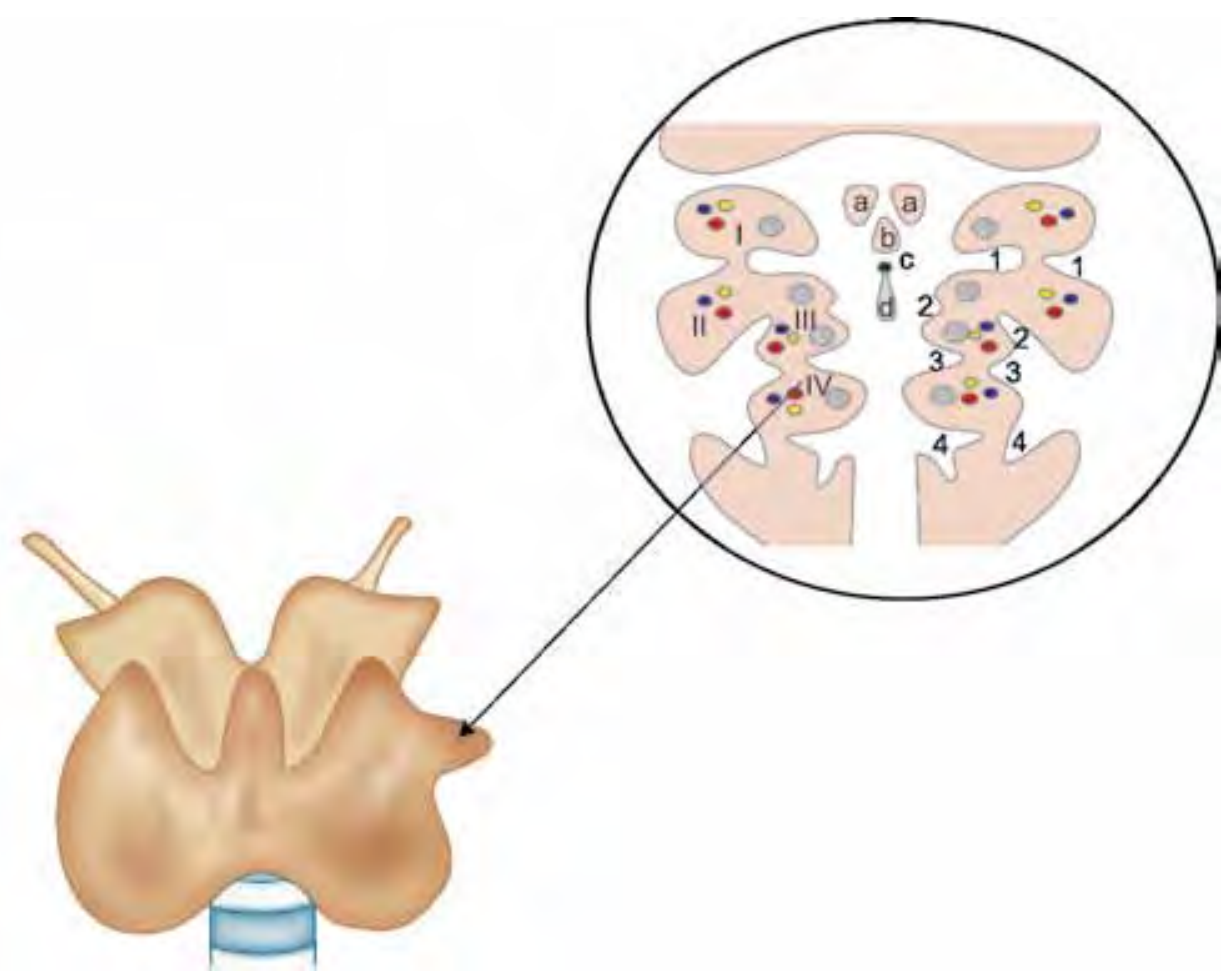

Fig. 1: Development of tubercle of Zuckerkandl

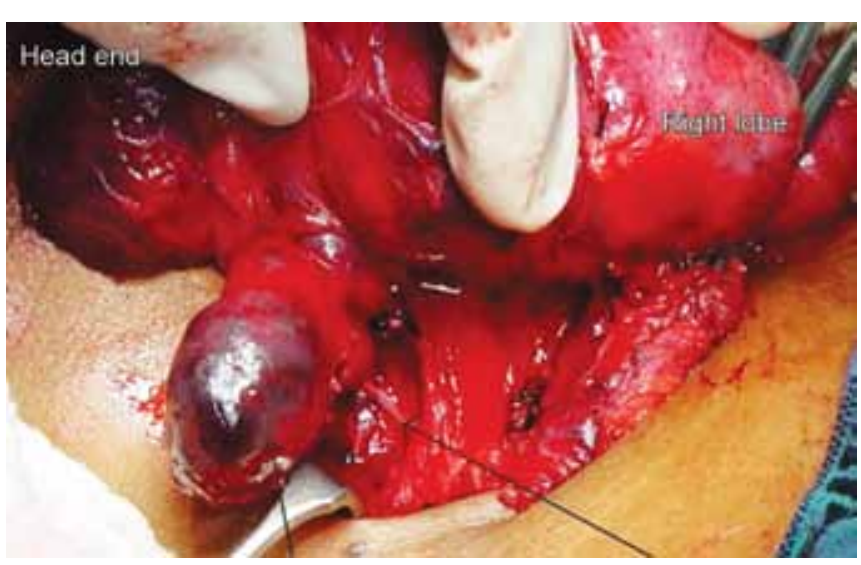

Fig. 2: Grade III tubercle

grade of TZ may cause severe pressure symptoms. Larger the TZ more is the pressure symptom. We would like to suggest that the goiter: TZ ratio is more important predictor of pressure symptom and not the actual size of the goiter. ${ }^{6}$

\section{PREVERTEBRAL SOFT-TISSUE MASS}

Measurement of prevertebral soft-tissue is commonly used to assess prevetebral anomalies like retropharyngeal abscess or injury to cervical spine. In presence of goiter the widened prevertebral tissue in usually due to enlarged $\mathrm{TZ}$, which may cause pressure symptoms.

Measurement of prevertebral soft-tissue taken at $C 4$ level correlates well with the grade of $\mathrm{TZ}$ and pressure symptoms. Sometimes measurement at $\mathrm{C} 3$ or $\mathrm{C} 5$ levels may be of help in TZ with anatomic variations. ${ }^{7}$

\section{MAY MIMIC PATHOLOGY}

Tubercle of Zuckerkandl is a normal surgical landmark with anatomic and radiologic variations. Computed tomography (CT) scan may mislead TZ which does not has nodular shape, particularly when the low neck is compromised by steak artifact from shoulders, where it may be mistaken for nodule or lymph node resulting in unnecessary biopsies/surgery. So, the radiologist should be careful not to unnecessary label TZ as a pathological structure. ${ }^{8}$

\section{NEW FASCIAL CONCEPT}

There is a fascial sleeve extending from the posterior ' $\mathrm{V}$ ' lip of the superior pole of thyroid which passes posteriorly. This on anteromedial rotation becomes the superficial vascular fascial layer. This encloses the TZ. Tubercle of Zuckerkandl is both the pointer to RLN and also separates superior and inferior parathyroid gland. In this situation, it is necessary to mobilize TZ and also rotate it almost $180^{\circ}$ anteriorly and medially to expose the RLN and also for the safe dissection of parathyroids. ${ }^{9}$

\section{FRIEND OR FOE}

The anatomy of the head and neck is by and large, fixed and predictable and in such situation TZ is an unpredictable occurrence if the surgeon is naive. It is one of the points where the nerve gets frequently injured, especially on the right-side. Most surgeons consider TZ as a foe initially which ultimately becomes the friend. ${ }^{10}$ 


\section{IMPORTANCE IN THYROID SURGERY}

Tubercle of Zuckerkandl is not only an important landmark, but also if not properly identified and carefully dissected, decreases the chances of nerve injury proportionately. The new concept of fascial plane separating the $\mathrm{TZ}$ and RLN reinforces the importance of identification $\mathrm{TZ}$ for safe dissection of parathyroid and RLN. The authors used TZ as a maker and a tool for safe thyroid surgery. ${ }^{11}$

In the changing paradigm of thyroid surgery $\mathrm{TZ}$, which was an inconstant landmark has now become a constant landmark for identification of RLN. The endocrine surgeon should be aware that it is more consistently found, usually larger on the right with anatomical variations and also might result in pressure symptoms especially in small goiters and becomes a friend as the surgeon experience increases.

\section{REFERENCES}

1. Yalcin B, Tatar I, Ozan H. The Zuckerkandl tubercle and the recurrent laryngeal nerve. Am J Surg 2008 Aug;196(2):311-312.

2. James YE, Doleagbenou A, Kassegne I, Biramah BT, Keke K, Dosseh ED, Ayite AE, James K. Zuckerkandl's tubercle: incidence and relationship with the inferior laryngeal nerve. Morphologie. 2014 Dec;98(323):171-175.
3. Gravante G, Delogu D, Rizzello A, Filingeri V. The Zuckerkandl tubercle. Am J Surg 2007 Apr;193(4):484-485.

4. Gregory R. Surgery of the thyroid and parathyroid glands: expert consult premium edition-enhanced online features and print. Elsevier Health Sciences; 2012.

5. Yalçin B, Ozan H. Relationship between the Zuckerkandl's tubercle and entrance point of the inferior laryngeal nerve. Clin Anat 2007 Aug;20(6):640-643. Erratum in: Clin Anat 2008 Mar;21(2):222.

6. Hisham AN, Aina EN. Zuckerkandl's tubercle of the thyroid gland in association with pressure symptoms: a coincidence or consequence? Aust N Z J Surg 2000 Apr;70(4):251-253.

7. Hisham AN, Sarojah A, Mastura T, Lim TO. Prevertebral soft-tissue measurements in thyroid enlargement: the value of lateral neck radiographs. Asian J Surg 2004 Jul;27(3): 172-175.

8. Lee TC, Selvarajan SK, Curtin H, Mukundan S. Zuckerkandl tubercle of the thyroid: a common imaging finding that may mimic pathology. AJNR Am J Neuroradiol 2012 Jun;33(6): 1134-1138.

9. Serpell JW. New operative surgical concept of two fascial layers enveloping the recurrent laryngeal nerve. Ann Surg Oncol 2010 Jun;17(6):1628-1636.

10. Chintamani. 'Friend or Foe' of a thyroid surgeon? The tubercle of Zuckerkandl. Indian J Surg 2013 Oct;75(5):337-338.

11. Rajapaksha A, Fernando R, Ranasinghe N, Iddagoda S. Morphology of the tubercle of Zuckerkandl and its importance in thyroid surgery. Ceylon Med J 2015 Mar;60(1):23-24. 